\title{
Pyogenic granuloma: An unusual cause of massive gastrointestinal bleeding from the small bowel
}

\author{
Dana C Moffatt MD FRCPC ${ }^{1}$, Paul Warwryko MD², Harminder Singh MD MPH FRCPC ${ }^{1}$
}

\begin{abstract}
DC Moffatt, P Warwryko, H Singh. Pyogenic granuloma: An unusual cause of massive gastrointestinal bleeding from the small bowel. Can J Gastroenterol 2009;23(4):261-264.
\end{abstract}

Small bowel hemorrhage is responsible for approximately $4 \%$ of all cases of gastrointestinal bleeding. The etiology of bleeding from the small bowel is a tumour in approximately $10 \%$ of cases. Pyogenic granuloma is a common inflammatory vascular tumour of the dermis, which rarely occurs in the gastrointestinal tract. Pyogenic granuloma is a rare cause of overt or obscure small bowel bleeding. The present paper reports the first case of pyogenic granuloma presenting as a massive gastrointestinal bleed, and reviews the relevant literature to date regarding the clinical presentation, diagnosis and management of this rare gastrointestinal lesion.

\section{Le granulome pyogène : Une cause inhabituelle d'hémorragie massive de l'intestin grêle}

\begin{abstract}
L'hémorragie de l'intestin grêle est responsable d'environ $4 \%$ de tous les cas d'hémorragies gastro-intestinales. Dans environ $10 \%$ des cas, l'étiologie du saignement de l'intestin grêle est une tumeur. Le granulome pyogène est une tumeur inflammatoire et vasculaire courante du derme, qu'on observe rarement dans le tube digestif. C'est une cause rare d'hémorragie manifeste ou occulte de l'intestin grêle. Le présent article présente le premier cas de granulome pyogène se manifestant sous forme d'hémorragie gastro-intestinale massive et passe en revue les publications pertinentes au sujet de la présentation clinique, du diagnostic et de la prise en charge de cette rare lésion gastro-intestinale.
\end{abstract}

Key Words: Obscure gastrointestinal bleeding; Pyogenic granuloma

astrointestinal (GI) bleeding in the small intestine - dis-

$J_{\text {tal }}$ to the duodenum - is an uncommon entity and is responsible for $4 \%$ of all cases of GI bleeding (1). The most common etiologies for small intestinal bleeding are angiodysplasias and tumours, responsible for approximately $70 \%$ and $10 \%$ of cases, respectively $(1,2)$. Pyogenic granuloma (PG) is a common inflammatory vascular tumour of the skin and oral cavity that has rarely been described in the GI tract as a source of obscure and overt bleeding. In the present report, we describe the first case of massive GI bleeding caused by a small bowel PG, and we review the relevant literature to date regarding the clinical presentation, diagnosis and management of this rare GI lesion.

\section{CASE PRESENTATION}

The case of a 78-year-old Caucasian man with longstanding anemia (hemoglobin $80 \mathrm{~g} / \mathrm{L}$ to $100 \mathrm{~g} / \mathrm{L}$ ) followed by a hematologist for suspected myelodysplasia is reported. On worsening of his anemia, and with decreasing serum ferritin and iron saturation levels, he was diagnosed with iron deficiency anemia and a GI source of blood loss was suspected. Diagnostic esophagogastroduodenoscopy, colonoscopy and small bowel follow-through did not reveal the source of bleeding. A technetium $99 \mathrm{~m}$-tagged red blood cell scan was performed and suggested bleeding in the right upper quadrant; however, the source was not clearly identified as being in the large or small bowel.

Shortly thereafter, the patient presented to hospital with presyncope, hemodynamic instability and large volume melena. He was hospitalized and required transfusion of eight units of packed red blood cells over a $24 \mathrm{~h}$ period. His nadir

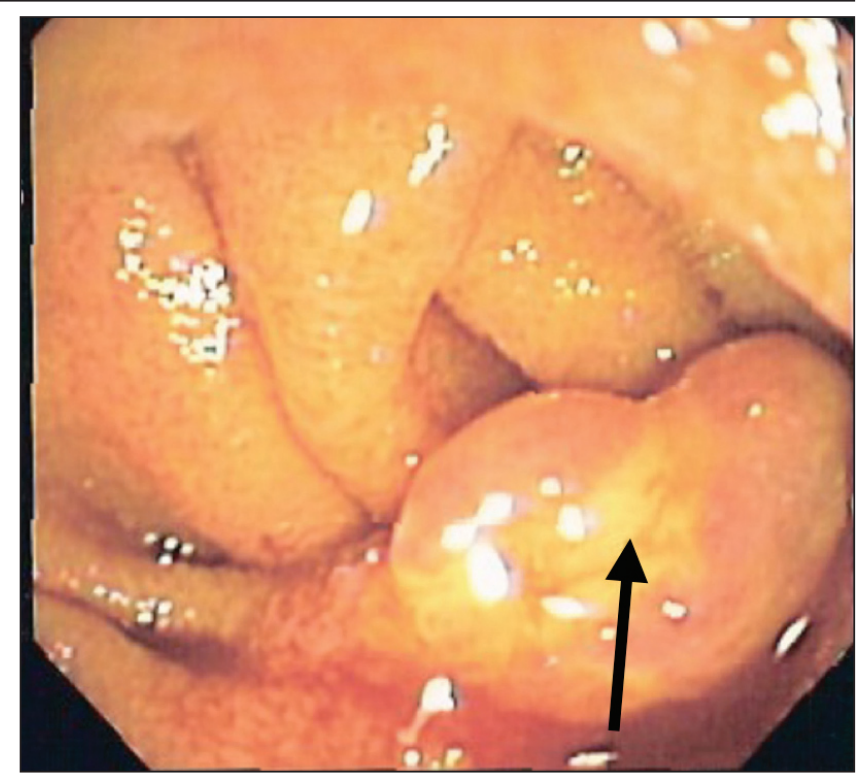

Figure 1) Jejunal pyogenic granuloma seen on push enteroscopy. The arrow indicates the distinctive white film coating

hemoglobin was $62 \mathrm{~g} / \mathrm{L}$, at which point he was transferred to the Health Sciences Centre at the University of Manitoba, Winnipeg, Manitoba, for further assessment and management. An urgent small bowel push enteroscopy identified a $2 \mathrm{~cm}$ polypoid lesion approximately $20 \mathrm{~cm}$ into the jejunum. The lesion was reddish-blue in colour, with a white coating and superficial ulceration (Figure 1). Biopsies were taken at which

${ }^{1}$ Department of Internal Medicine; ${ }^{2}$ Department of Pathology, University of Manitoba, Winnipeg, Manitoba

Correspondence: Dr Harminder Singh, Section of Gastroenterology, University of Manitoba, 804-715 McDermot Avenue,

Winnipeg, Manitoba R3E 3P4. Telephone 204-480-1311, fax 204-789-3972, e-mail singh@cc.umanitoba.ca

Received for publication September 10, 2008. Accepted September 26, 2008 


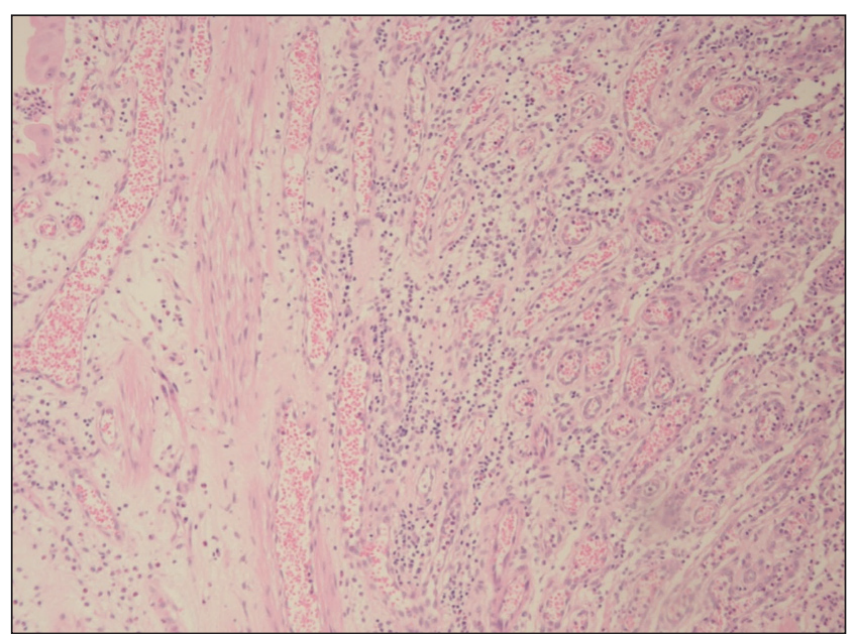

Figure 2) Microscopy image of postsurgery pyogenic granuloma tissue showing dense vascular proliferation and inflammatory reaction in the stroma, consistent with pyogenic granulomas (hematoxylin and eosin stain, original magnification $\times 40$ )

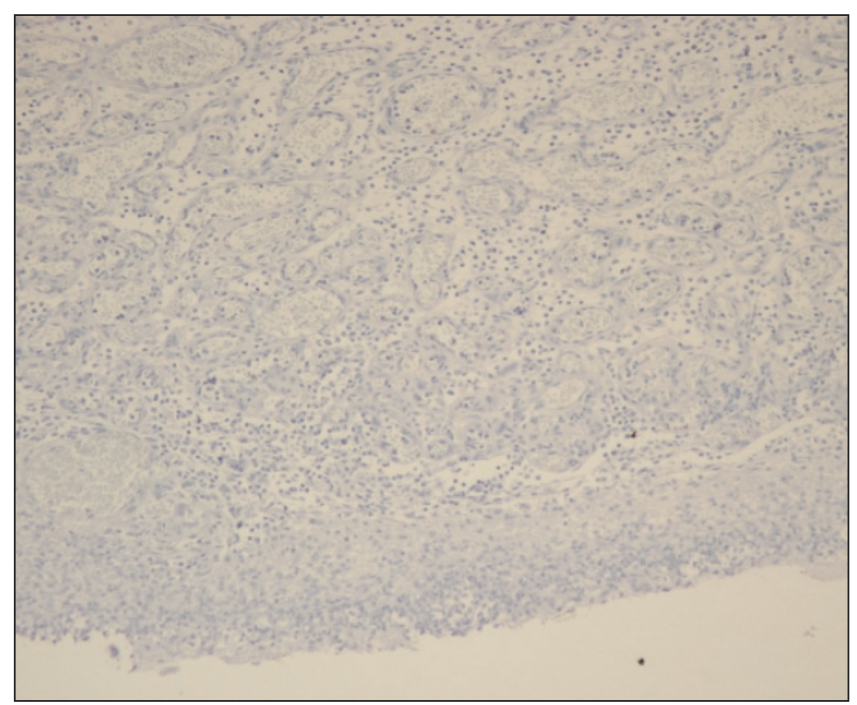

Figure 3) Immunohistochemical study in the same case shows negative staining for human herpes virus-8 (immunoperoxidase stain, original magnification $\times 40$ )

point active bleeding occurred. Due to hemodynamic instability and ongoing bleeding, surgical consultation was obtained and the patient underwent a resection of $40 \mathrm{~cm}$ of proximal small bowel. After surgery, there was no further bleeding and the patient was discharged 10 days after admission. One year later, the patient's hemoglobin remained stable at $130 \mathrm{~g} / \mathrm{L}$ and he is no longer iron deficient.

Pathological analysis of the initial biopsy specimen and the small bowel specimen revealed the lesion to be a $2 \mathrm{~cm}$ polypoid capillary hemangioma filled with a dense neutrophil infiltrate (Figure 2). The periodic acid-Schiff stain and the immunohistochemistry stain for human herpes virus (HHV)-8 (Figure 3) were negative. The CD31/34 stains were positive for endothelial cells within the capillary loops (Figure 4) and confirmed the diagnosis of PG.

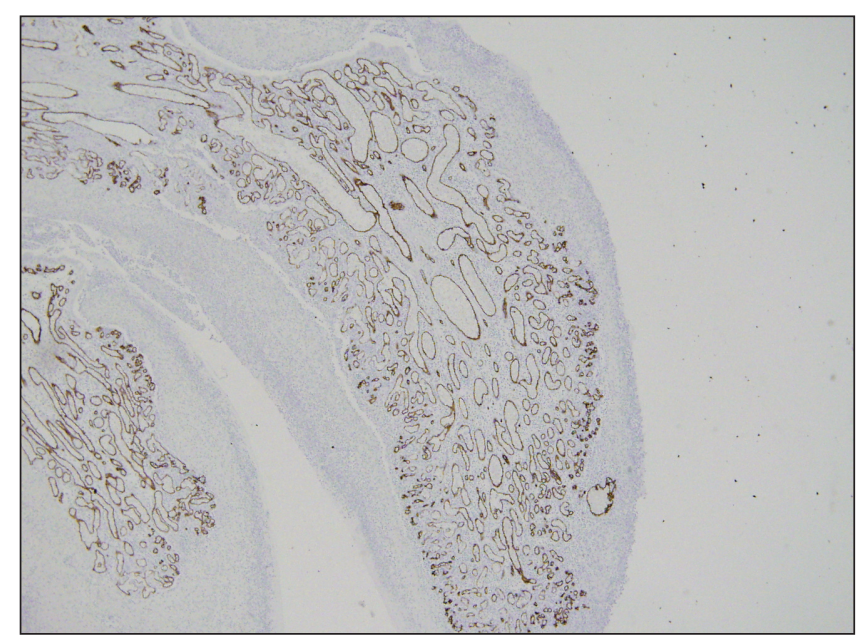

Figure 4) Immunohistochemical staining for CD34 shows the endothelial cell population (immunoperoxidase stain, original magnification $\times 10)$. CD31 and factor VIII stains were also used to identify endothelial cells (data not shown)

\section{LITERATURE REVIEW}

The English language literature from 1968 to July 2008 was reviewed using PubMed. The search terms "pyogenic granuloma" combined with "gastrointestinal", "endoscopy" and/or "hemorrhage" were used to locate all available articles, and used references included in all relevant case reports to locate additional reports. In total, 20 reports that documented a total of 23 possible cases of GI PG were retrieved.

\section{DISCUSSION}

PG is an inflammatory vascular lesion that occurs most commonly in the epidermis and oral cavity. It is generally described as a red, polypoid mass of apparent granulation tissue that bleeds easily. Both sexes are affected equally and it occurs throughout all age groups (3). The most common areas for PG to occur are on the extremities and in the oral cavity. PG lesions have been noted to originate from the mucosa or submucosa only. The cause is believed to be the result of local trauma or irritation, although there may be an increased incidence during pregnancy, and therefore, a hormonal mechanism may exist. For PG outside the GI tract, local excision is generally curative (4).

Microscopically, PG is best described as a capillary hemangioma arranged in a lobular pattern, filled with clusters of small capillary vessels and lined by a single layer of bland endothelial cells. The stroma is often edematous and filled with a dense neutrophilic infiltrate (5). The lesion may be confused with bacilliary angiomatosis or Kaposi's sarcoma, and therefore, periodic acid-Schiff stain and immunohistochemical stains for HHV-8 are recommended to rule out an underlying infection (5). Stains for tissue factor VIII and CD31/34 should be performed to ensure that endothelial cells line the capillary loops, a common feature of PG (4).

To date, there have been a total of 23 cases of possible GI PG reported in the literature (Table 1). Most patients have been of middle to late age. There appears to be a higher incidence in Asian populations, although this may represent a reporting bias. Many earlier case reports did not rule out HHV-8 infection or bacilliary angiomatosis and therefore may not represent true PG lesions. The etiology of these lesions is not clear, although PG of the GI tract may also be related to local trauma or irritation 
TABLE 1

Previously reported cases of gastrointestinal pyogenic granuloma

\begin{tabular}{|c|c|c|c|c|c|}
\hline Author (reference) & $\begin{array}{c}\text { Subject age } \\
\text { years }\end{array}$ & Sex & Anatomical location & Symptoms & Treatment \\
\hline Okumura et al (14) & 49 & Female & Esophagus & None & Endoscopic polypectomy \\
\hline Meuwissen et al (8) & 37 & Male & Ileum & None & Laser ablation \\
\hline Iwakubo et al (13) & 30 & Female & Ileum & Melena & Surgical resection \\
\hline Hizawa et al (15) & 26 & Female & Ileum & None & Surgical resection \\
\hline Iwasaka et al (11) & 55 & Male & Colon & Melena & Surgical resection \\
\hline Craig et al (16) & 31 & Male & Esophagus & Dysphagia & Endoscopic polypectomy \\
\hline Yao et al (17) & 71 & Female & Ileum & Anemia & Surgical resection \\
\hline Yao et al (17) & 56 & Male & Jejunum & Melena & Surgical resection \\
\hline Yao et al (17) & 55 & Male & Colon & Anemia & Surgical resection \\
\hline Hirakawa et al (18) & 60 & Male & Duodenum & Anemia & Endoscopic polypectomy \\
\hline Manabe et al (19) & 45 & Male & Esophagus & Dysphagia & None \\
\hline Motohashi et al (20) & 58 & Female & Ileum & Anemia & Surgical resection \\
\hline Kusakabe et al (12) & 82 & Male & Stomach & Melena & Angiographic embolization \\
\hline Nakaya et al (21) & 59 & Female & Colon & Positive FOBT & Surgical resection \\
\hline Lee et al (10) & 69 & Female & Common bile duct & Cholangitis & Endoscopic polypectomy \\
\hline Shirakawa et al (22) & 72 & Male & Ileum & Anemia & Endoscopic polypectomy \\
\hline van Eeden et al (5) & 55 & Female & Ileum & Anemia & Surgical resection \\
\hline van Eeden et al (5) & 55 & Female & Esophagus & Dysphagia & Endoscopic polypectomy \\
\hline Tajika et al (7) & 63 & Male & Esophagus & None & Endoscopic polypectomy \\
\hline Gonzalez-Vela et al (9) & 63 & Female & Colon & Hematochezia & Endoscopic polypectomy \\
\hline Field et al (23) & 80 & Female & Colon & Hematochezia & Endoscopic polypectomy \\
\hline Hoekstra et al (6) & 15 & Male & Esophagus & Dysphagia & Endoscopic polypectomy \\
\hline Moparty et al (24) & 26 & Male & Rectum & None & Endoscopic polypectomy \\
\hline
\end{tabular}

FOBT Fecal occult blood test

because it is in the dermis. Two cases of PG in the esophagus were reported after resolution of erosive esophagitis $(6,7)$. Another case report (8) suggested the development of a PG in the terminal ileum after recovery from Campylobacter enteritis. Clinically, patients with PG can be asymptomatic or present with overt bleeding from the lesion $(7,9)$. PG has also caused common bile duct obstruction in a single case (10), and dysphagia in two others $(5,11)$. The present case is the first report of a patient with PG presenting with hemodynamically significant GI bleeding requiring massive transfusion of blood products.

Endoscopically, PG lesions are described by almost all authors as polypoid lesions that are bluish-red in colour and with an opaque or white film covering. In the present case, and in several others that involved overt bleeding, the lesions have been visibly ulcerated $(5,12,13)$. The size of the lesions have ranged from $7 \mathrm{~mm}$ to $30 \mathrm{~mm}$ in diameter.

Treatment of GI PG has been successfully completed with endoscopic polypectomy in nine cases and surgical removal in another 10 cases (Table 1). Angiographic embolization and laser ablation have also been described $(8,12)$. In all reported cases, patients were free of symptoms at the end of the follow-up period, and there have been no documented recurrences or malignant transformations.

\section{CONCLUSION}

PG is an uncommon lesion of the GI tract, with a propensity to bleed that may be asymptomatic or may cause iron deficiency anemia. Rarely, these lesions can be associated with overt bleeding and are very rarely life-threatening. PG may be amenable to endoscopic diagnosis, given its unusual colour and distinct white film coating. Once diagnosed, endoscopic polypectomy appears to be as equally effective and safe as surgical excision and, therefore, should be considered the therapy of choice. PG should be added to the list of luminal disorders that can be responsible for GI bleeding.

\section{REFERENCES}

1. Lewis BS. Small intestinal bleeding. Gastroenterol Clin North Am 2000;29:67-95.

2. Zuckerman GR, Prakash C, Askin MP, Lewis BS. AGA technical review on the evaluation and management of occult and obscure gastrointestinal bleeding. Gastroenterology 2000;118:201-21.

3. Rosai J. Ackerman's Surgical Pathology. 8th edn, St Louis: Mosby Company, 1995.

4. Enzinger FM WS. Soft Tissue Tumors. 4th edn. St. Louis: Mosby Company, 2001.

5. van Eeden S, Offerhaus GJ, Morsink FH, van Rees BP, Busch OR, van Noesel CJ. Pyogenic granuloma: An unrecognized cause of gastrointestinal bleeding. Virchows Arch 2004:444:590-3.

6. Hoekstra ER, Fockens P, Scholten P. A 15-year-old boy with an esophageal pyogenic granuloma and subsequent Barrett's esophagus (with videos). Gastrointest Endosc 2007;65:1086-8.

7. Tajika M, Nakamura T, Kawai H, et al. Short-term development of esophageal pyogenic granuloma observed on endoscopy. Gastrointest Endosc 2006;64:269-70.

8. Meuwissen SG, Willig AP, Hausman R, Starink TM, MathusVliegen EM. Multiple angiomatous proliferations of ileal stoma following Campylobacter enteritis. Effect of laser photocoagulation. Dig Dis Sci 1986;31:327-32.

9. Gonzalez-Vela M, Val-Bernal J, Garijo M, Garcia-Suarez C. Pyogenic granuloma of the sigmoid colon. Ann Diagn Pathol 2005;9:106-9.

10. Lee CK, Dong SH, Jung SH, et al. Pyogenic granuloma of the common bile duct in a patient with choledochoduodenostomy. Endoscopy 2007;39(Suppl 1):E282-3.

11. Iwasaka C, Yazu T, Suehiro A, et al. [A case of pyogenic granuloma in the sigmoid colon.] Nippon Shokakibyo Gakkai Zasshi 1995;92:885-8. 
12. Kusakabe A, Kato H, Hayashi K, et al. Pyogenic granuloma of the stomach successfully treated by endoscopic resection after transarterial embolization of the feeding artery. J Gastroenterol 2005;40:530-5.

13. Iwakubo A, Tsuda T, Kubota M, Wakabayashi J, Kobayashi K, Morita K. [Diagnostic 99mTc-labeled red blood cells scintigraphy in gastrointestinal tract bleeding from an intestinal pyogenic granuloma.] Kaku Igaku 1989;26:1439-43.

14. Okumura T, Tanoue S, Chiba K, Tanaka S. Lobular capillary hemangioma of the esophagus. A case report and review of the literature. Acta Pathol Jpn 1983;33:1303-8.

15. Hizawa K, Iida M, Matsumoto T, Kohrogi N, Yao T, Fujishima M. Neoplastic transformation arising in Peutz-Jeghers polyposis. Dis Colon Rectum 1993;36:953-7.

16. Craig RM, Carlson S, Nordbrock HA, Yokoo H. Pyogenic granuloma in Barrett's esophagus mimicking esophageal carcinoma. Gastroenterology 1995;108:1894-6.

17. Yao T, Nagai E, Utsunomiya T, Tsuneyoshi M. An intestinal counterpart of pyogenic granuloma of the skin. A newly proposed entity. Am J Surg Pathol 1995;19:1054-60.
18. Hirakawa K, Aoyagi K, Yao T, Hizawa K, Kido H, Fujishima M. A case of pyogenic granuloma in the duodenum: Successful treatment by endoscopic snare polypectomy. Gastrointest Endosc 1998;47:538-40.

19. Manabe T, Goto H, Enya M, et al. [A case of pyogenic granuloma in the cervical esophagus.] Nippon Shokakibyo Gakkai Zasshi 1998;95:230-2.

20. Motohashi Y, Hisamatsu T, Ikezawa T, et al. [A case of pyogenic granuloma in the small intestine.] Nippon Shokakibyo Gakkai Zasshi 1999;96:1396-400.

21. Nakaya T, Tokunaga T, Aono S, et al. Pyogenic granuloma of the descending colon. Endoscopy 2007;39 (Suppl 1):E259-60.

22. Shirakawa K, Nakamura T, Endo M, Suzuki K, Fujimori T, Terano A. Pyogenic granuloma of the small intestine. Gastrointest Endosc 2007;66:827-8.

23. Field M, Inston N, Zanetto U, Cruikshank N. Pyogenic granuloma of the colon. Int J Colorectal Dis 2007;22:1139-40.

24. Moparty B, Xiao SY, Bhutani MS. Pyogenic granuloma presenting as a rectal polyp at the site of a previous polypectomy. Endoscopy 2006;38(Suppl 2):E2-3. 


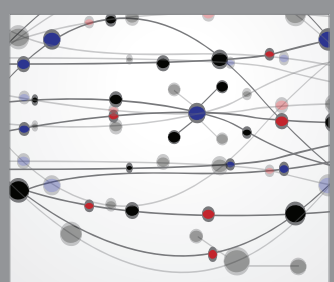

The Scientific World Journal
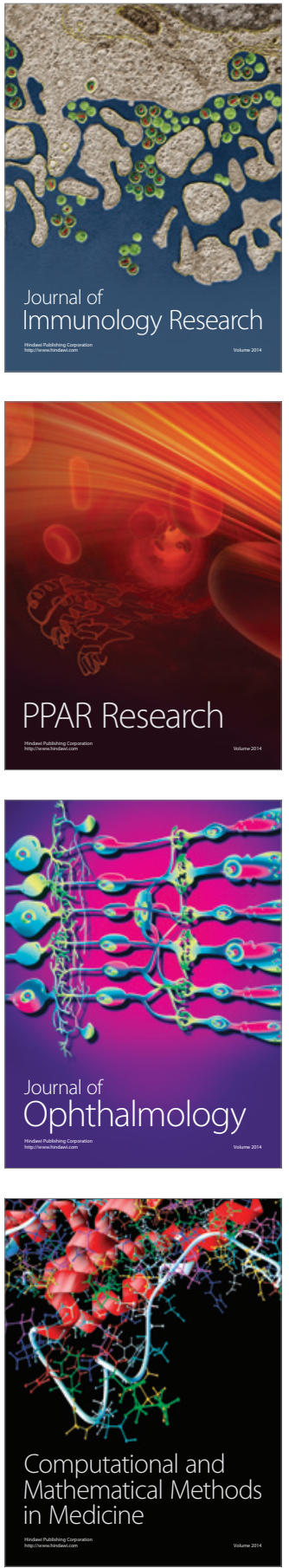

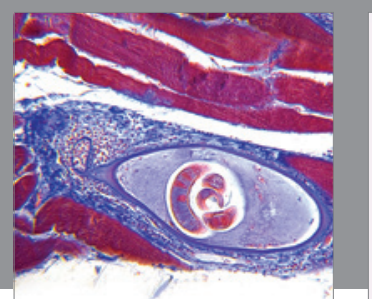

Gastroenterology Research and Practice

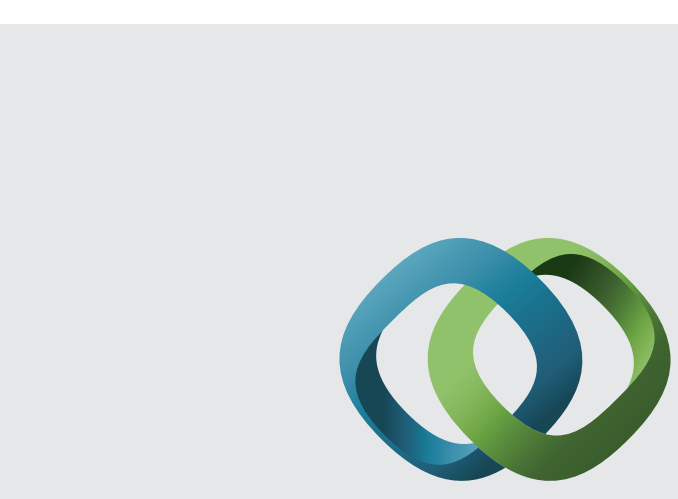

\section{Hindawi}

Submit your manuscripts at

http://www.hindawi.com
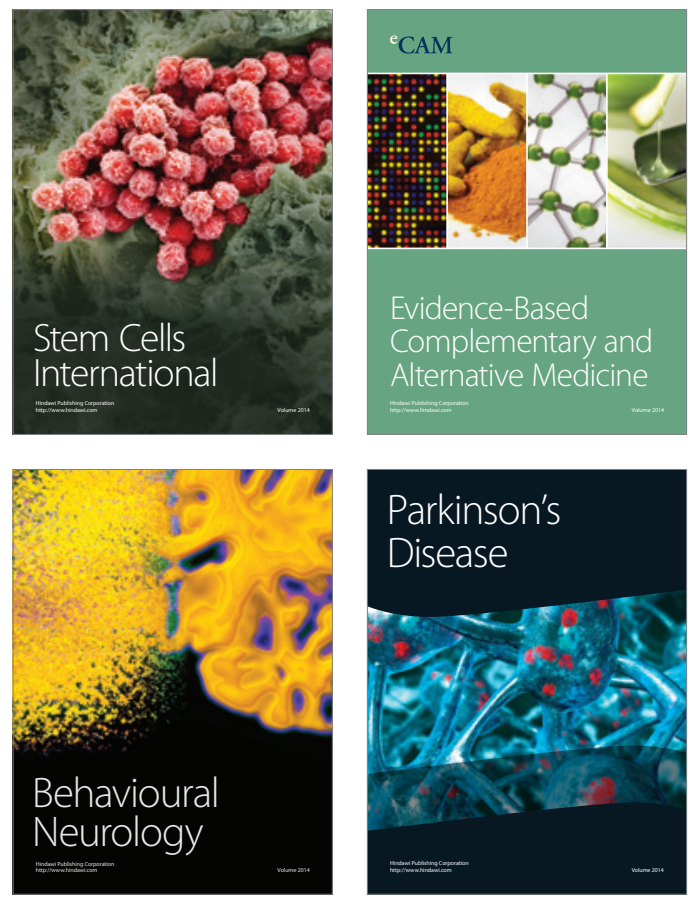
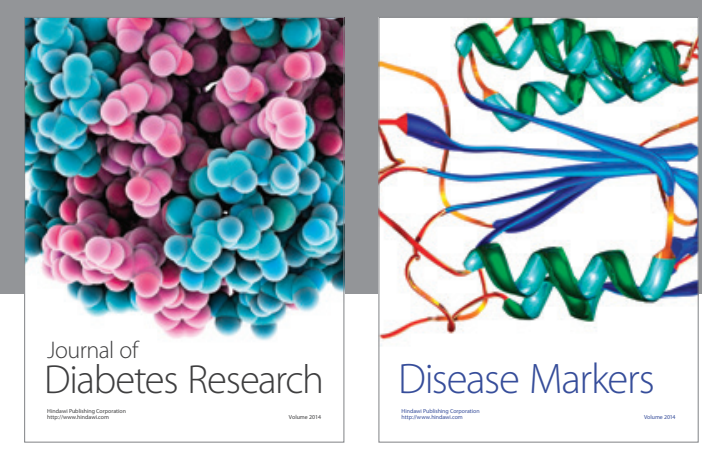

Disease Markers
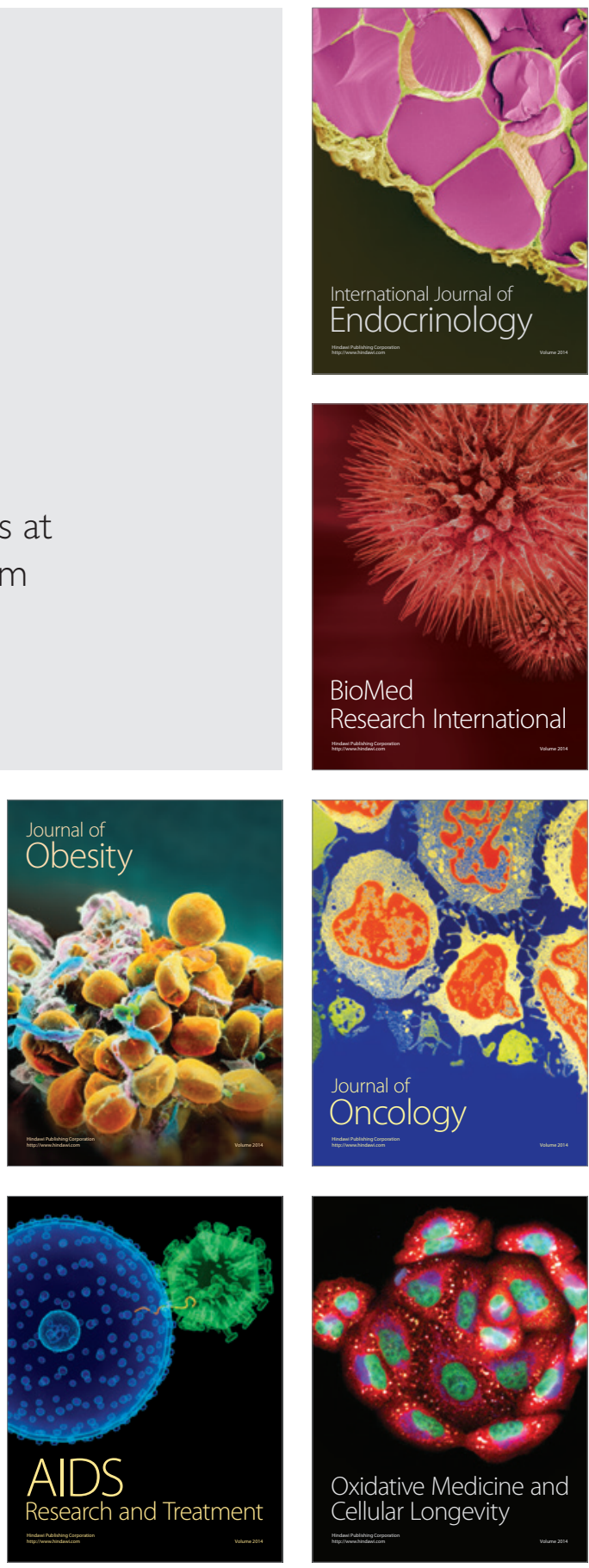